\title{
Thermal engineering for sustainable technologies
}

\author{
Surendra Singh Kachhwaha ${ }^{1}$ - Nishith B. Desai ${ }^{2}$ Santanu Bandyopadhyay ${ }^{3}$
}

Published online: 11 April 2021

(C) The Author(s), under exclusive licence to Springer-Verlag GmbH Germany, part of Springer Nature 2021

Thermal engineering is playing an important role in development of sustainable technologies especially in the scope of renewable energy, energy storage, and energy saving. This issue is devoted to the theme of thermal engineering for sustainable technologies covering few papers presented in the 12th International Conference on Thermal Engineering: Theory and Applications (ICTEA2019). The ICTEA conference series was inspired to assist and provide opportunities for professional development among scientists and engineers working in the field of thermal engineering and its applications. The vital need for such developments persists for a long time, despite the dedicated commitment of regional governments in developing countries to raise the standard of undergraduate education and to create world-class research capabilities in the institutions of higher education. The purpose of starting an international conference like ICTEA is to meet this requirement and to provide a well-structured platform to expedite interdisciplinary research activities and productivity in the region, as well as providing a well-established point of contact and worldwide networking. Such a conference can serve as a focal point for the gathering of scientists and engineers. The theme "Thermal Engineering" has been selected as an umbrella title for the conference series because of its encompassing meaning, and the wide range

Nishith B. Desai

nishithdesai17@gmail.com;nbdes@mek.dtu.dk

Surendra Singh Kachhwaha

Surendra.Singh@sot.pdpu.ac.in

Santanu Bandyopadhyay

santanub@iitb.ac.in

1 Department of Mechanical Engineering, Pandit Deendayal Energy University, Raisan, Gandhinagar, Gujarat 382007, India

2 Department of Mechanical Engineering, Technical University of Denmark, Nils Koppels Allé, Building 403, 2800 Kongens Lyngby, Denmark

3 Department of Energy Science and Engineering, Indian Institute of Technology Bombay, Powai, Mumbai 400 076, India of research areas covered under this theme are of equally important in the developing and developed world. A wide range of interdisciplinary topics related to the environment, energy, petroleum, and construction are the obvious examples of thermal engineering applications that are crucial for the industrial and economic development.

The first conference on Thermal Engineering was held in Beirut, Lebanon, from 31st May to 4th June, 2004. Looking at the success beyond expectations, the series continued, and the next conference was held in the United Arab Emirates from 3rd January to 6th January, 2006. Since then, Ryerson University, Canada, has been organizing the conference series in Thermal Engineering and continued at Jordan, Oman, Morocco, and Doha. The 12th conference of the series was held in India at Pandit Deendayal Petroleum University, Gandhinagar, Gujarat.

After a careful selection procedure, invitations were sent to the ICTEA 2019 authors to prepare extended articles based on the relevance to the journal and the reviews of the conference version of the papers. Out of seventeen submitted articles, after thorough reviewing procedures, seven were finally accepted for this special issue section of Clean Technologies and Environmental Policy (CTEP). We appreciate the willingness of the authors for helping in organizing this special issue. We are thankful to the CTEP journal publisher, Editor in Chief, and Production Editor for supporting this publication. We hope that the readers will be benefitted from the content of this special issue.

Publisher's Note Springer Nature remains neutral with regard to jurisdictional claims in published maps and institutional affiliations. 